\title{
Publishing Science in Tribology: The Past, Present and Future of Tribology Letters
}

\author{
Ashlie Martini $^{1} \cdot$ David L. Burris $^{2} \cdot$ Juliette Cayer-Barrioz $^{3} \cdot$ Nicholas D. Spencer $^{4}$ (1)
}

Received: 6 April 2021 / Accepted: 26 April 2021

(c) The Author(s) 2021

\begin{abstract}
The last 25 years have seen immense changes, both in the world generally and in scientific publishing. It is now hard to imagine that our original editorial responsibilities included managing filing cabinets full of manuscripts and making frequent trips to the post office! In this first Invited Viewpoint, we have invited ourselves to highlight some of the key breakthroughs that have been made on topics that are within the scope of Tribology Letters, i.e., breakthroughs in the science of tribology. We also bring your attention to some unique, existing features of the journal, as well as new ways in which Tribology Letters will be more functional for you in the future. Finally, we share our views on publishing tribology research more generally, with the aim of encouraging publication decisions that benefit the tribology community as a whole.
\end{abstract}

Keywords Tribology Letters · Tribology Publishing · Breakthroughs in Tribology

\section{Tribology Letters Scope, History and Impact}

Tribology Letters recently clocked up its first quarter century. During that time, we have published over 3000 articles within the general area of "tribological science"-understanding the mechanisms that lead to tribological phenomena-on topics ranging from controversies in the tribology of curling [1-3] to the tribocorrosion of lollipops [4].

First, what do we mean by tribological science? Tribology is the science and engineering of interacting surfaces in relative motion and related phenomena, including lubrication, adhesion, friction and wear. At Tribology Letters, founded by two surface scientists, we are interested in the SCIENCE of tribology, focusing on mechanistic insights and the fundamental understanding of tribological phenomena.

Nicholas D. Spencer

spencer@mat.ethz.ch

1 School of Engineering, University of California, Merced, CA 95343, USA

2 Department of Mechanical Engineering, University of Delaware, Newark, DE 19716, USA

3 Laboratoire de Tribologie et Dynamique des Systèmes, Ecole Centrale de Lyon, CNRS UMR5513, 69134 Ecully, France

4 Laboratory for Surface Science \& Technology, ETH Zurich, CH-8093 Zurich, Switzerland
Tribology Letters has published many excellent papers within the topic of tribological science over the years. Here, we would like to highlight just a few of the most impactful articles-chosen by the editors as examples of papers that have changed the way the community thinks about various aspects of tribology.

Over the last two decades, contributions to Tribology Letters have helped shape how we understand the physical origins of friction and how those insights can be applied to practical friction control. Early experimental work showing how the stick-slip characteristics of atomic-scale friction measurements can map directly to the lattice of model samples [5] suggested that fundamental interatomic potentials are the physical basis of friction. This insight paved the way for contact-damping effects [6-9], thermolubricity [10, 11], superlubricity $[12,13]$ and other means of friction control.

This basic science met engineering at the macroscale interface. Studies with stable polymer interfaces, for example, have shown compelling evidence of macroscale thermolubricity [14]. Small-amplitude, high-frequency oscillations, the mechanical analog to thermal energy, have been used to activate slip and suppress friction of many practical materials systems [15]. Diamond-like carbons (DLCs) and 2D materials such as single-crystal $\mathrm{MoS}_{2}$ and graphene achieve "superlow" friction coefficients by effectively flattening the potential-energy (p.e.) landscape [16-19]. By manipulating the p.e. landscape in this way, 
oriented 1D nanotube forests have been used to toggle between very high and very low friction [20,21].

Elastohydrodynamic lubrication (EHL) has long been a mystery from the scientific perspective. However, in the last fifteen years, new methods, both experimental and computational, have started to reveal not only what happens in EHL, but how it happens. For example, an experimental study that enabled scientists to "see" inside an EHL contact showed that EHL friction arises from the shear of a highly pressurized and confined "fluid" that is trapped between the elastic contact of the two opposing surfaces [22]. The relative contributions of the Couette and Poiseuille terms to friction were subsequently differentiated for Newtonian fluids [23]. Tribology Letters has also hosted a lively and engaging debate [24,25] over the most appropriate rheological models for EHL studies involving tribological scientists from around the world.

The journal has published many other studies aimed at understanding and controlling friction in the full-fluid-film or boundary/mixed lubrication regimes. Such approaches consist of modifying the surface topography (see, for instance, [26] for full-film regimes and [27] for molecular films) and/or the surface chemistry via adsorption of or functionalization with appropriate species [28-35].

Tribology Letters has been home to many papers focused on understanding tribofilms. It is well known that lubricant additives protect surfaces via films that form, wear and reform during operation. However, these processes cannot be directly observed. So, tribology scientists have developed creative ways to monitor and learn about this important process; see, for example, [36-38]. Similar methods have been used to study transfer-film formation, stability and suppression of friction and wear of high-performance carbon and $\mathrm{MoS}_{2}$-based solid lubricants $[39,40]$.

Some of these high-performance solid lubricants were tested in low-earth orbit outside the International Space Station in one of the most ambitious undertakings in the tribology literature [41]; in fact, these were the first active experiments in the Materials International Space Station Experiments (MISSE) program. A key discovery of that effort was the tribochemical and tribological degradation of an ultra-low-wear alumina-PTFE composite originally chosen for its chemical inertness. This observation motivated follow-up studies showing how tribochemistry, catalyzed by the nanofiller and supported by environmental moisture, stabilizes the interface and ultimately enables ultra-low wear rates $[42,43]$. The absence of environmental humidity in the space environment precluded these favorable tribochemical processes, which disrupted the primary wear-reduction mechanism.

Tribology Letters has published influential papers on the tribology-biology interface, which have helped us to understand the structure and properties of natural tribological structures such as cartilage [44-48], probe the biological response of epithelial or endothelial cells to friction [49-52], or even describe novel systems with the potential for imitating natural tribological materials [53-55]. Clearly, this is a booming field and we expect this to continue to be an important part of the journal.

A great debate in the tribology community has to do with the meaning of "contact" at the nanoscale. At larger scales, real or apparent contact area can be defined and quantified relatively easily. However, for single asperities or nanoscale devices, where the contact comprises a few to hundreds of atoms, the definition of contact is less clear. Many papers published in Tribology Letters have tackled this challenge. Some of the most impactful papers on this topic were published by the late Mark Robbins [35, 56, 57]. Mark, who served on the Editorial Board of our journal, was a giant in the field of tribology science and he will be missed by us all. Tribology Letters is currently preparing a special issue "Mark Robbins, in memoriam"-in memory of Mark and his contributions to our field and our community.

In addition to the standard article types, Tribology Letters has published many impactful Methods papers. Such papers focus on new experimental or data-analysis methods, testing procedures or theoretical approaches that are relevant to the field of tribology. Methods papers are an important article type because they enable researchers to not only read about others' results, but to reproduce them and learn about best practices. Tribology Letters has published Methods papers on topics including AFM calibration [58-60], measurement of hydrodynamic oil films using ultrasonic reflection [61], measurement of real contact areas [62, 63], analytical models (including freely available code for their solution) for atomic friction [64] and in situ methods for tribology generally [65].

Lastly, Tribology Letters publishes Review articles, by invitation, that summarize the state of the art in specific aspects of tribological science. The most highly cited paper published in Tribology Letters to-date is "The history and mechanisms of ZDDP" by Hugh Spikes [66]. The review presented this important topic from a scientific perspective and has shaped the way the tribology community thinks about ZDDP and similar additives. A review of ionic liquids has also racked up hundreds of downloads in the past few years and particularly focused on the fundamental mechanisms of ionic liquid lubrication at the nanoscale [67]. Lastly, a highly cited review focusing on the tribology of human skin summarized the history and latest research in this close-to-home topic [68]. The best Review papers are those that not only summarize a topic, but place it in a broader context and then demonstrate how various studies complement or contrast with each other. 


\section{New Journal Features}

Preprint sharing is already an important part of the publication process in many fields, especially in the physics community, which started the arXiv in 1991. The fields of biology and medicine have also established their own preprint sharing servers in the meantime. We are pleased to announce that Springer Nature is now offering In Review to Tribology Letters authors. Manuscripts from authors who opt in will be publicly accessible as preprints via Research Square, a platform designed to promote open research discussions before and after publication. This service accelerates visibility among funders and colleagues, enables citation during peer review and offers community-wide feedback and discussion both prior to and after publication. The use of In Review is, of course, optional and authors will be asked during the submission process whether they want their preprint to be shared using this service.

Another benefit of publishing with Tribology Letters is SharedIt, which is a Springer Nature content-sharing initiative that allows you to post unique links to your article anywhere for non-commercial, personal use, including on social-media platforms, your own websites, or an institutional repository. SharedIt enables authors to share their work with their friends, colleagues, students and social media followers. These links provide free full-text viewonly access to all Tribology Letters articles by anyone from anywhere. To share any Tribology Letters paper, simply locate the paper on our website, scroll to the bottom of the page and press the 'Get shareable link' button.

\section{Innovative Manuscript Types}

You probably saw our first "Challenge" article on contact mechanics [69], in which a number of tribologists, worldwide, were asked to predict adhesion between two surfaces of defined topographies. The resulting article, with its 35 authors, as well as a series of nine articles [70-78] that go into more detail in the methods involved and discuss some related controversies, constitutes a tremendously instructive insight into the state of the art of the contact mechanics field, contrasting the strengths and weaknesses of a wide variety of approaches. We are open to your suggestions for further challenge articles!

Data Notes are a new type of article that focuses on big datasets that are generally difficult to obtain, but of interest to the community for further interpretation, analysis or application. These might be, for example, obtained with a unique instrument or collected from a one-time event such as a space mission or an earthquake. The data have to be of interest to the community, unique and deemed by the reviewers to be reliable. More information can be found in our instructions for authors [79]. Our first Data Note has just appeared [80], and the corresponding $150+$ sets of friction data are available free-of-charge on the data repository Dryad [81].

Lastly, this paper is the first example of a new article type, Invited Viewpoint [82]. This type of article is intended to provide authors with a means of expressing a scientific opinion, with the goal of encouraging communication within the tribology community. Invited Viewpoint articles need not report new data or methods, but should be focused on some aspect, or perhaps controversy, within the scope of tribological science. Invited Viewpoint articles are by invitation only.

\section{Why Publish in Tribology Journals?}

Our focus is on the science of tribology, rather than on purely engineering topics, which are the specialties of other journals. We thus aim to publish papers that move forward our understanding of tribology fundamentals, whether this be in friction, lubrication, wear, or the contact interface itself. One challenge that authors face is that there are so many different tribology journals available. It is therefore important that journals clarify their scope or at least their emphasis areas within tribology. Understanding the emphases of the many different tribology journals can both help authors place their papers appropriately and guide readers in their literature searches.

A related challenge within the tribological community is that higher-impact journals in other fields such as physics or surface chemistry solicit tribology-themed papers. These journals have attracted and received the credit for some of our best tribology research. The net result is reduced impact factors for tribology journals, which then increases the pressure on us to publish our best tribology research elsewhere. However, by taking advantage of the new initiatives reviewed here and submitting our best tribological science papers to Tribology Letters, we can reverse this negative cycle and benefit the entire tribology community. Tribological science has a bright future and we look forward to working with you to publish your latest and most significant research in this exciting field!

Funding Open access funding provided by Swiss Federal Institute of Technology Zurich. 


\section{Declarations}

Conflict of interest All authors declare that they have no conflict of interest.

Open Access This article is licensed under a Creative Commons Attribution 4.0 International License, which permits use, sharing, adaptation, distribution and reproduction in any medium or format, as long as you give appropriate credit to the original author(s) and the source, provide a link to the Creative Commons licence, and indicate if changes were made. The images or other third party material in this article are included in the article's Creative Commons licence, unless indicated otherwise in a credit line to the material. If material is not included in the article's Creative Commons licence and your intended use is not permitted by statutory regulation or exceeds the permitted use, you will need to obtain permission directly from the copyright holder. To view a copy of this licence, visit http://creativecommons.org/licenses/by/4.0/.

\section{References}

1. Penner, A.R.A.: Scratch-guide model for the motion of a curling rock. Tribol. Lett. 67, 35 (2019). https://doi.org/10.1007/ s11249-019-1144-0

2. Lozowski, E., Shegelski, M.R.A., Hawse, M., Lowry, S., Sample, C., Reid, M.: Comment on "a scratch-guide model for the motion of a curling rock." Tribol. Lett. 68, 2 (2020). https://doi.org/10. 1007/s11249-019-1242-z

3. Penner, A.R.: Reply to the comment on "a scratch-guide model for the motion of a curling rock." Tribol. Lett. 68, 1 (2020). https:// doi.org/10.1007/s11249-019-1243-y

4. Rowe, K.G., Harris, K.L., Schulze, K.D., Marshall, S.L., Pitenis, A.A., Urueña, J.M., Niemi, S.R., Bennett, A.I., Dunn, A.C., Angelini, T.E., Sawyer, W.G.: Lessons from the lollipop: biotribology, tribocorrosion, and irregular surfaces. Tribol. Lett. 56, 273-280 (2014). https://doi.org/10.1007/s11249-014-0407-z

5. Bennewitz, R., Gnecco, E., Gyalog, T., Meyer, E.: Atomic friction studies on well-defined surfaces. Tribol. Lett. 10, 51-56 (2001). https://doi.org/10.1023/A:1009078329570

6. Johnson, K.L., Woodhouse, J.: Stick-slip motion in the atomic force microscope. Tribol. Lett. 5, 155-160 (1998). https://doi.org/ 10.1023/a:1019106127794

7. Gosvami, N.N., Filleter, T., Egberts, P., Bennewitz, R.: Microscopic friction studies on metal surfaces. Tribol. Lett. 39, 19-24 (2010). https://doi.org/10.1007/s11249-009-9508-5

8. Nakano, K.: Two dimensionless parameters controlling the occurrence of stick-slip motion in a 1-DOF system with Coulomb friction. Tribol. Lett. 24, 91-98 (2006). https://doi.org/10.1007/ s11249-006-9107-7

9. Roth, R., Glatzel, T., Steiner, P., Gnecco, E., Baratoff, A., Meyer, E.: Multiple slips in atomic-scale friction: an indicator for the lateral contact damping. Tribol. Lett. 39, 63-69 (2010). https:// doi.org/10.1007/s11249-009-9567-7

10. Zhao, X., Hamilton, M., Sawyer, W.G., Perry, S.S.: Thermally activated friction. Tribol. Lett. 27, 113-117 (2007). https://doi. org/10.1007/s11249-007-9220-2

11. Jinesh, K.B., Valk, H., Dienwiebel, M., Frenken, J.W.M.: Thermolubricity in atomic-scale friction. Phys. Rev. B 78, 155440 (2008). https://doi.org/10.1103/PhysRevB.78.155440

12. Hirano, M., Shinjo, K., Kaneko, R., Murata, Y.: Observation of superlubricity by scanning tunneling microscopy. Phys. Rev. Lett. 78, 1448-1451 (1997). https://doi.org/10.1103/PhysRevLett.78. 1448
13. Dienwiebel, M., Verhoeven, G.S., Pradeep, N., Frenken, J.W.M., Heimberg, J.A., Zandbergen, H.W.: Superlubricity of graphite. Phys. Rev. Lett. 92, 126101 (2004). https://doi.org/10.1103/PhysR evLett.92.126101

14. Burris, D.L., Perry, S.S., Sawyer, W.G.: Macroscopic evidence of thermally activated friction with polytetrafluoroethylene. Tribol. Lett. 27, 323-328 (2007). https://doi.org/10.1007/ s11249-007-9237-6

15. Popov, V.L., Starcevic, J., Filippov, A.E.: Influence of ultrasonic in-plane oscillations on static and sliding friction and intrinsic length scale of dry friction processes. Tribol. Lett. 39, 25-30 (2010). https://doi.org/10.1007/s11249-009-9531-6

16. Liang, T., Sawyer, W.G., Perry, S.S., Sinnott, S.B., Phillpot, S.R.: First-principles determination of static potential energy surfaces for atomic friction in $\mathrm{MoS}_{2}$ and $\mathrm{MoO}_{3}$. Phys. Rev. B 77, 1-6 (2008). https://doi.org/10.1103/PhysRevB.77.104105

17. Feng, X., Kwon, S., Park, J.Y., Salmeron, M.: Superlubric sliding of graphene nanoflakes on graphene. ACS Nano 7, 1718-1724 (2013). https://doi.org/10.1021/nn305722d

18. Erdemir, A., Eryilmaz, O.L., Fenske, G.: Synthesis of diamondlike carbon films with superlow friction and wear properties. J. Vac. Sci. Technol. A Vacuum, Surfaces, Film. 18, 1987-1992 (2000). https://doi.org/10.1116/1.582459

19. Wang, J., Wang, F., Li, J., Wang, S., Song, Y., Sun, Q., Jia, Y.: Theoretical study of superlow friction between two single-side hydrogenated graphene sheets. Tribol. Lett. 48, 255-261 (2012). https://doi.org/10.1007/s11249-012-0015-8

20. Dickrell, P.L., Pal, S.K., Bourne, G.R., Muratore, C., Voevodin, A.A., Ajayan, P.M., Schadler, L.S., Sawyer, W.G.: Tunable friction behavior of oriented carbon nanotube films. Tribol. Lett. 24, 85-90 (2006). https://doi.org/10.1007/s11249-006-9162-0

21. Dickrell, P.L., Sinnott, S.B., Hahn, D.W., Raravikar, N.R., Schadler, L.S., Ajayan, P.M., Sawyer, W.G.: Frictional anisotropy of oriented carbon nanotube surfaces. Tribol. Lett. 18, 59-62 (2005). https://doi.org/10.1007/s11249-004-1752-0

22. Spikes, H., Jie, Z.: History, origins and prediction of elastohydrodynamic friction. Tribol. Lett. 56, 1-25 (2014). https://doi. org/10.1007/s11249-014-0396-y

23. de Vicente, J., Stokes, J., Spikes, H.: The frictional properties of newtonian fluids in rolling-sliding soft-EHL contact. Tribol. Lett. 20, 273-286 (2005). https://doi.org/10.1007/ s11249-005-9067-3

24. Bair, S., Vergne, P., Kumar, P., Poll, G., Krupka, I., Hartl, M., Habchi, W., Larsson, R.: Comment on "History, origins and prediction of elastohydrodynamic friction" by Spikes and Jie. Tribol Lett 58, 16 (2015). https://doi.org/10.1007/s11249-015-0481-x

25. Spikes, H., Zhang, J.: Reply to the comment by Scott Bair, Philippe Vergne, Punit Kumar, Gerhard Poll, Ivan Krupka, Martin Hartl, Wassim Habchi, Roland Larson on "History, origins and prediction of elastohydrodynamic friction" by Spikes and Jie in Tribology Letters. Tribol. Lett. 58, 17 (2015). https://doi.org/10. 1007/s11249-015-0483-8

26. Etsion, I.: Improving tribological performance of mechanical components by laser surface texturing. Tribol. Lett. 17, 733-737 (2004). https://doi.org/10.1007/s11249-004-8081-1

27. Gao, J., Luedtke, W., Landman, U.: Structures, solvation forces and shear of molecular films in a rough nano-confinement. Tribol. Lett. 9, 3-13 (2000). https://doi.org/10.1023/A:1018840023845

28. Müller, M., Lee, S., Spikes, H.A., Spencer, N.D.: The influence of molecular architecture on the macroscopic lubrication properties of the brush-like Co-polyelectrolyte Poly(L-lysine)-gpoly(ethylene glycol) (PLL-g-PEG) adsorbed on oxide surfaces. Tribol. Lett. 15, 395-405 (2003). https://doi.org/10.1023/B:TRIL. $0000003063.98583 . \mathrm{bb}$ 
29. Fan, J., Müller, M., Stöhr, T., Spikes, H.: Reduction of friction by functionalised viscosity index improvers. Tribol. Lett. 28, 287-298 (2007). https://doi.org/10.1007/s11249-007-9272-3

30. Bielecki, R.M., Benetti, E.M., Kumar, D., Spencer, N.D.: Lubrication with oil-compatible polymer brushes. Tribol. Lett. 45, 477-487 (2012). https://doi.org/10.1007/s11249-011-9903-6

31. Bielecki, R.M., Crobu, M., Spencer, N.D.: Polymer-brush lubrication in oil: sliding beyond the stribeck curve. Tribol. Lett. 49, 263-272 (2013). https://doi.org/10.1007/s11249-012-0059-9

32. Spikes, H.: Friction modifier additives. Tribol. Lett. 60, 5 (2015). https://doi.org/10.1007/s11249-015-0589-z

33. Campen, S., Green, J., Lamb, G., Atkinson, D., Spikes, H.: On the Increase in boundary friction with sliding speed. Tribol Lett $\mathbf{4 8}$, 237-248 (2012). https://doi.org/10.1007/s11249-012-0019-4

34. Berman, A., Drummond, C., Israelachvili, J.: Amontons' law at the molecular level. Tribol. Lett. 4, 95 (1998). https://doi.org/10. 1023/A:1019103205079

35. He, G., Robbins, M.O.: Simulations of the kinetic friction due to adsorbed surface layers. Tribol. Lett. 10, 7-14 (2001). https://doi. org/10.1023/A:1009030413641

36. Martin, J.M.: Antiwear mechanisms of zinc dithiophosphate: a chemical hardness approach. Tribol. Lett. 6, 1-8 (1999). https:// doi.org/10.1023/A:1019191019134

37. Morina, A., Neville, A., Priest, M., Green, J.H.: ZDDP and MoDTC interactions and their effect on tribological performance - tribofilm characteristics and its evolution. Tribol. Lett. 24, 243 256 (2006). https://doi.org/10.1007/s11249-006-9123-7

38. Aktary, M., McDermott, M.T., McAlpine, G.A.: Morphology and nanomechanical properties of zddp antiwear films as a function of tribological contact time. Tribol. Lett. 12, 155-162 (2002). https:// doi.org/10.1023/A:1014755123184

39. Dvorak, S.D., Wahl, K.J., Singer, I.L.: In situ analysis of third body contributions to sliding friction of a $\mathrm{Pb}-\mathrm{Mo}-\mathrm{S}$ coating in dry and humid air. Tribol. Lett. 28, 263-274 (2007). https://doi.org/ 10.1007/s11249-007-9270-5

40. Scharf, T.W., Singer, I.L.: Quantification of the thickness of carbon transfer films using Raman tribometry. Tribol. Lett. 14, 137-145 (2003). https://doi.org/10.1023/A:1021942822261

41. Krick, B.A., Sawyer, W.G.: Space tribometers: design for exposed experiments on orbit. Tribol. Lett. 41, 303-311 (2011). https://doi. org/10.1007/s11249-010-9689-y

42. Pitenis, A.A., Ewin, J.J., Harris, K.L., Sawyer, W.G., Krick, B.A.: In vacuo tribological behavior of polytetrafluoroethylene (PTFE) and alumina nanocomposites The importance of water for ultralow wear. Tribol. Lett. 53, 189-197 (2014). https://doi.org/10.1007/ s11249-013-0256-1

43. Pitenis, A.A., Harris, K.L., Junk, C.P., Blackman, G.S., Sawyer, W.G., Krick, B.A.: Ultralow Wear PTFE and alumina composites: It is all about tribochemistry. Tribol. Lett. 57, 4 (2015). https://doi. org/10.1007/s11249-014-0445-6

44. Bonnevie, E.D., Baro, V.J., Wang, L., Burris, D.L.: In situ studies of cartilage microtribology: roles of speed and contact area. Tribol. Lett. 41, 83-95 (2011). https://doi.org/10.1007/ s11249-010-9687-0

45. Crockett, R., Roos, S., Rossbach, P., Dora, C., Born, W., Troxler, H.: Imaging of the surface of human and bovine articular cartilage with ESEM and AFM. Tribol Lett 19, 311-317 (2005). https://doi. org/10.1007/s11249-005-7448-2

46. Merkher, Y., Sivan, S., Etsion, I., Maroudas, A., Halperin, G., Yosef, A.: A rational human joint friction test using a human cartilage-on-cartilage arrangement. Tribol. Lett. 22, 29-36 (2006). https://doi.org/10.1007/s11249-006-9069-9

47. Ruggiero, A., Gomez, E., D'Amato, R.: Approximate analytical model for the squeeze-film lubrication of the human ankle joint with synovial fluid filtrated by articular cartilage. Tribol Lett 41, 337-343 (2011). https://doi.org/10.1007/s11249-010-9710-5
48. Burris, D.L., Ramsey, L., Graham, B.T., Price, C., Moore, A.C.: How sliding and hydrodynamics contribute to articular cartilage fluid and lubrication recovery. Tribol. Lett. 67, 46 (2019). https:// doi.org/10.1007/s11249-019-1158-7

49. Dunn, A.C., Zaveri, T.D., Keselowsky, B.G., Sawyer, W.G.: Macroscopic friction coefficient measurements on living endothelial cells. Tribol. Lett. 27, 233-238 (2007). https://doi.org/10.1007/ s11249-007-9230-0

50. Dunn, A.C., Cobb, J.A., Kantzios, A.N., Lee, S.J., Sarntinoranont, M., Tran-Son-Tay, R., Sawyer, W.G.: Friction coefficient measurement of hydrogel materials on living epithelial cells. Tribol. Lett. 30, 13-19 (2008). https://doi.org/10.1007/s11249-008-9306-5

51. Straehla, J.P., Limpoco, F.T., Dolgova, N.V., Keselowsky, B.G., Sawyer, W.G., Perry, S.S.: Nanomechanical probes of single corneal epithelial cells: shear stress and elastic modulus. Tribol Lett 38, 107-113 (2010). https://doi.org/10.1007/s11249-010-9579-3

52. Pitenis, A.A., Urueña, J.M., Hart, S.M., O’Bryan, C.S., Marshall, S.L., Levings, P.P., Angelini, T.E., Sawyer, W.G.: Frictioninduced inflammation. Tribol. Lett. 66, 81 (2018). https://doi.org/ 10.1007/s11249-018-1029-7

53. Nakashima, K., Sawae, Y., Murakami, T.: Influence of protein conformation on frictional properties of poly (vinyl alcohol) hydrogel for artificial cartilage. Tribol Lett 26, 145-151 (2007). https://doi.org/10.1007/s11249-006-9185-6

54. Cui, L., Chen, J., Yan, C., Xiong, D.: Articular cartilage inspired the construction of LTi-DA-PVA composite structure with excellent surface wettability and low friction performance. Tribol. Lett. 69, 41 (2021). https://doi.org/10.1007/ s11249-021-01416-y

55. Shi, Y., Xiong, D., Li, J., Li, L., Liu, Q., Dini, D.: Tribological rehydration and its role on frictional behavior of PVA/GO hydrogels for cartilage replacement under migrating and stationary contact conditions. Tribol. Lett. 69, 1-14 (2021). https://doi. org/10.1007/s11249-020-01371-0

56. Luan, B., Robbins, M.O.: Hybrid atomistic/continuum study of contact and friction between rough solids. Tribol. Lett. 36, 1-16 (2009). https://doi.org/10.1007/s11249-009-9453-3

57. Cheng, S., Robbins, M.O.: Defining contact at the atomic scale. Tribol. Lett. 39, 329-348 (2010). https://doi.org/10.1007/ s11249-010-9682-5

58. Piétrement, O., Beaudoin, J., Troyon, M.: A new calibration method of the lateral contact stiffness and lateral force using modulated lateral force microscopy. Tribol. Lett. 7, 213-220 (1999). https://doi.org/10.1023/A:1019150226828

59. Garabedian, N.T., Khare, H.S., Carpick, R.W., Burris, D.L.: AFM at the macroscale : methods to fabricate and calibrate probes for millinewton force measurements. Tribol. Lett. 67, 21 (2019). https://doi.org/10.1007/s11249-019-1134-2

60. Bhattacharjee, A., Garabedian, N.T., Evans, C.L., Burris, D.L.: Traceable Lateral Force Calibration (TLFC) for atomic force microscopy. Tribol. Lett. 68, 111 (2020). https://doi.org/10. 1007/s11249-020-01349-y

61. Dwyer-Joyce, R., Harper, P., Drinkwater, B.: A method for the measurement of hydrodynamic oil films using ultrasonic reflection. Tribol. Lett. 17, 337-348 (2004). https://doi.org/10. 1023/B:TRIL.0000032472.64419.1f

62. Krick, B.A., Vail, J.R., Persson, B.N.J., Sawyer, W.G.: Optical in situ micro tribometer for analysis of real contact area for contact mechanics, adhesion, and sliding experiments. Tribol. Lett. 45, 185-194 (2012). https://doi.org/10.1007/s11249-011-9870-y

63. Bennett, A.I., Harris, K.L., Schulze, K.D., Urueña, J.M., McGhee, A.J., Pitenis, A.A., Müser, M.H., Angelini, T.E., Sawyer, W.G.: Contact measurements of randomly rough surfaces. Tribol. Lett. 65, 134 (2017). https://doi.org/10.1007/s11249-017-0918-5 
64. Dong, Y., Vadakkepatt, A., Martini, A.: Analytical models for atomic friction. Tribol. Lett. 44, 367 (2011). https://doi.org/10. 1007/s11249-011-9850-2

65. Spikes, H.A.: In situ methods for tribology research. Tribol. Lett. 14, 1 (2003). https://doi.org/10.1023/A:1021790313293

66. Spikes, H.: The history and mechanisms of ZDDP. Tribol. Lett. 17, 469-489 (2004). https://doi.org/10.1023/B:TRIL.0000044495. 26882.b5

67. Palacio, M., Bhushan, B.: A review of ionic liquids for green molecular lubrication in nanotechnology. Tribol. Lett. 40, 247268 (2010). https://doi.org/10.1007/s11249-010-9671-8

68. Derler, S., Gerhardt, L.C.: Tribology of skin: review and analysis of experimental results for the friction coefficient of human skin. Tribol Lett 45, 1-27 (2012). https://doi.org/10.1007/ s11249-011-9854-y

69. Müser, M.H., Dapp, W.B., Bugnicourt, R., et al.: Meeting the contact-mechanics challenge. Tribol. Lett. 65, 118 (2017). https:// doi.org/10.1007/s11249-017-0900-2

70. Bugnicourt, R., Sainsot, P., Dureisseix, D., Gauthier, C., Lubrecht, A.A.: FFT-based methods for solving a rough adhesive contact: description and convergence study. Tribol. Lett. 66, 29 (2018). https://doi.org/10.1007/s11249-017-0980-z

71. Ciavarella, M.A.: Comment on "Meeting the contact-mechanics challenge" by Muser et al. Tribol. Lett. 66, 37 (2018). https://doi. org/10.1007/s11249-018-0985-2

72. Müser, M.H.: Response to "A comment on meeting the contact(mechanics) challenge." Tribol. Lett. 66, 38 (2018). https://doi. org/10.1007/s11249-018-0986-1

73. Afferrante, L., Bottiglione, F., Putignano, C., Persson, B.N.J., Carbone, G.: Elastic contact mechanics of randomly rough surfaces: an assessment of advanced asperity models and persson's theory. Tribol. Lett. 66, 75 (2018). https://doi.org/10.1007/ s11249-018-1026-X

74. Wang, A., Müser, M.H.: Gauging Persson theory on adhesion. Tribol. Lett. 65, 103 (2017). https://doi.org/10.1007/ s11249-017-0886-9
75. Bennett, A.I., Rohde, S., Harris, K.L., Schulze, K.D., Urueña, J.M., Pitenis, A.A., Ifju, P.G., Angelini, T.E., Müser, M.H., Sawyer, W.G.: Deformation measurements of randomly rough surfaces. Tribol. Lett. 65, 123 (2017). https://doi.org/10.1007/ s11249-017-0901-1

76. Bennett, A.I., Harris, K.L., Schulze, K.D., Urueña, J.M., McGhee, A.J., Pitenis, A.A., Müser, M.H., Angelini, T.E., Sawyer, W.G.: Contact measurements of randomly rough surfaces. Tribol. Lett. 65, 134 (2017). https://doi.org/10.1007/s11249-017-0918-5

77. $\mathrm{Wu}$, J.J.: Numerical simulation on the adhesive contact between rough surfaces with bi-conjugate gradient stabilized method. Tribol. Lett. 65, 151 (2017). https://doi.org/10.1007/ s11249-017-0930-9

78. McGhee, A.J., Pitenis, A.A., Bennett, A.I., Harris, K.L., Schulze, K.D., Urueña, J.M., Ifju, P.G., Angelini, T.E., Müser, M.H., Sawyer, W.G.: Contact and deformation of randomly rough surfaces with varying root-mean-square gradient. Tribol. Lett. 65, 157 (2017). https://doi.org/10.1007/s11249-017-0942-5

79. https://www.springer.com/journal/11249/submission-guidelines\# Instructions\%20for\%20Authors_Data\%20Note\%20Articles

80. Vellore, A., Romero Garcia, S., Johnson, D., Martini, A.: Ambient and nitrogen environment friction data for various materials $\&$ surface treatments for space applications. Tribol. Lett. 69, 10 (2021). https://doi.org/10.1007/s11249-020-01391-w

81. https://datadryad.org/stash/dataset/doi:10.6071/M33M4Q

82. https://www.springer.com/journal/11249/submission-guidelines\# Instructions \%20for\%20Authors_Invited\%20Viewpoints\%20(by\% 20invitation\%20only)

Publisher's Note Springer Nature remains neutral with regard to jurisdictional claims in published maps and institutional affiliations. 